\title{
Hepatitis A Virus Infections in Travelers, 1988-2004
}

\author{
Margot Mutsch, ${ }^{1}$ Virginie Masserey Spicher, ${ }^{2}$ Christoph Gut, ${ }^{1}$ and Robert Steffen ${ }^{1}$ \\ 'Division of Epidemiology and Prevention of Communicable Diseases and World Health Organization Collaborating Centre for Travelers' Health, \\ Institute of Social and Preventive Medicine, University of Zurich, Zurich, and ' ${ }^{2}$ wiss Federal Office of Public Health, Berne, Switzerland
}

Background. Uncertainty exists about the current risk of hepatitis A virus infection in nonimmune travelers to destinations with high or intermediate risk of transmission. We analyzed recent epidemiological data on imported hepatitis A to determine region-specific attack rates and incidences.

Methods. Surveillance data on hepatitis A virus infections diagnosed during 1988-2004 were evaluated on the basis of notification by laboratories, additional reports of physicians, and traveler's statistics. This study focuses on international travelers with hepatitis A virus infection detected after their return to Switzerland.

Results. The rate of imported hepatitis A virus infections decreased 75\% from 1988 to 2004 and accounted overall for $42 \%$ of all hepatitis A cases reported in Switzerland. The actual incidence of hepatitis A in travelers to countries of high or intermediate risk of transmission was 3.0-11.0 per 100,000 person-months abroad for all travelers and 6.0-28.0 per 100,000 for those presumed to be nonimmune. The actual proportion of those visiting friends and relatives among patients with hepatitis A has increased to $28.2 \%$, with children aged $0-14$ years predominating. Reductions in the incidence by hepatitis A vaccination were estimated to vary between $35.0 \%$ and $61.8 \%$ for different destinations.

Conclusions. The risk of hepatitis A virus infections has decreased by a factor of 10-50-fold over time, compared with findings from older studies. The risk, however, remains very considerable at many destinations, including frequently visited places, such as Mexico. Children of immigrants are a high-risk population. Strategies are needed to reach those at highest risk.

Hepatitis A virus (HAV) infection traditionally has been considered the most frequent vaccine-preventable infection among nonimmune travelers who visited developing countries [1]. More recently it has been demonstrated that this first rank belongs to influenza [2]. Additionally, a recent Canadian survey suggested that the monthly incidence of 3 cases per 1000 travelers, derived from a follow-up study 2 decades ago, now might be an overestimation. However, the authors concluded that the 10-fold-lower incidence they extrapolated may have been influenced by a large proportion of travelers to comparatively low-risk destinations in the Caribbean [3]. This prompted us to analyze HAV infections imported to Switzerland from 1988 to 2004

Received 23 August 2005; accepted 10 November 2005; electronically published 11 January 2006.

Presented in part: 9th Conference of the International Society of Travel Medicine, Lisbon, 1-4 May 2005 (abstract IC05.01).

Reprints or correspondence: Dr. Margot Mutsch, University of Zurich, Div. of Epidemiology and Prevention of Communicable Diseases, Travel Clinic Hirschengraben 84, CH-8001 Zurich, Switzerland (muetsch@ifspm.unizh.ch).

Clinical Infectious Diseases 2006; 42:490-7

(C) 2006 by the Infectious Diseases Society of America. All rights reserved. $1058-4838 / 2006 / 4204-0009 \$ 15.00$ and to compare the results with the first studies conducted in the 1970s $[4,5]$. For the past 10 years, more than one-third of all cases of hepatitis A diagnosed in Switzerland have been acquired abroad. It is thus relevant for public health and for individual travelers' health to estimate region-specific incidences.

\section{METHODS}

Study population. Acute viral hepatitis A was a notifiable disease in Switzerland throughout the study period from 1988 to 2004 (and before). All laboratories are requested to report positive results of anti-HAV IgM antibody measurement to the authorities. Additionally, the physician in charge of the patient is requested to submit detailed information about the patient's demographic characteristics, clinical assessment and course of the disease, vaccination status, potential places of exposure, and potential secondary spread. Mainly symptomatic infections were documented unless there were other reasons for serological testing reported (e.g., screening of children following suspected exposure). On the basis of the proportion of missing laboratory or physician reports, it is estimated that $\sim 80 \%$ of $\mathrm{HAV}$ infections are reported. 
To compare data over time more robustly, the study period was grouped into three 5- to 6-year intervals. Also, destinationspecific information was compared with data collected from 1971 to 1981 [4, 5]. Patients' ages, initially analyzed in eighteen 5 -year categories, is here summarized in five 15-year groups.

Traveler statistics collected by the Swiss Federal Office of Statistics for 1988 to 2002 [6] were used as denominator to calculate the attack rates and incidences; the 2003 and 2004 data had to be estimated, because travelers' statistics were not yet available. Information sources for travel statistics included national tourist offices, national offices of statistics, embassies, and the World Tourism Organization to collate data of arrivals of Swiss residents to various countries or regions worldwide ( $>1$ day of stay). Missing travel statistics for a few years had to be estimated when countries failed to provide data, such as the former Yugoslavia during its breakup. Travel regions were coded as described by the United Nations Development Agency [7]. Both the attack rate per trip to a destination and the incidence per month of stay abroad are described. The mean duration of stay at the destination and the proportion of those already immune against hepatitis A were derived from Swiss data from airport surveys $[8,9]$ and unpublished estimates by experts. The mean travel duration provided consistent information when compared with a cohort of Swiss travelers to tropical and subtropical destinations [2].

Statistical analysis. Data were analyzed using Stata statistical software, version 8.2 (Stata). The crude attack rates per 100,000 travelers (with 95\% CIs) were calculated by using the number of reported HAV cases as numerator and the estimated total number of travelers to a specific region in the defined time range from the travel database as denominator. To obtain incidences per month for nonimmune travelers, average duration of stay and the proportion of those with previous immunity were taken into account.

Differences in proportions of the demographic and clinical variables were compared by 2 -tailed Pearson's $\chi^{2}$ square and by Fisher's exact test. Trends across time groups were evaluated by the nonparametric test for trend developed by Cuzick [10], an extension of the Wilcoxon rank sum test. The level of statistical significance was set at <.05. To determine independent risk factors associated with travel history and with exposure to an infected person, respectively, adjusted ORs were calculated by stepwise logistic regression. The incidence data of the prevaccination era (1971-1993) were approximated by potential functions $\left(y=a x^{-\beta}\right.$, where $y$ is region-specific incidence, $a$ is slope of the curve, $x$ is time [e.g., year of reporting], and $\beta$ is region-specific factor) and were extrapolated to the recent time period (2000-2004) to achieve an incidence estimate accounting for factors others than HAV vaccination, such as changes in hygienic conditions at the destination. The immunity-related reduction in incidence was then estimated by calculating the proportion of the difference between the region-specific extrapolated incidence and the observed incidence in relation to the extrapolated one.

\section{RESULTS}

Laboratory reports were submitted for $7751 \mathrm{HAV}$ infections for the total study period, and from these, 6592 physician's reports $(85.0 \%)$ could be assessed for detailed information. Among these, 2784 (42.2\%) reported a travel history, 2581 (92.7\% of the imported cases) provided destination-specific data, and another 2631 (39.9\%) were clearly indicated to have acquired HAV infection in Switzerland. For the remaining 1177 cases $(17.9 \%)$, no presumed site of infection was noted.

Although in the beginning of the study period up to 942 HAV infections were recorded per year, a substantial decrease in the total annual number of cases was observed. Since 2001, less than 200 cases per year were reported, which corresponds to an annual incidence of $\leqslant 2.5$ cases of HAV infection per 100,000 residents. The ratio of male patients to female patients was 1.7 and did not vary significantly between groups with or without physician reports nor between infections imported or acquired in Switzerland (table 1). Recent travel was the major exposure risk reported, and it accounted on average for $42.2 \%$ (range, 33.3\%-58.8\%) of all HAV infections (mean, 164 cases per year; range, 51-277 cases per year). In the travel-associated subgroup, a contact with contaminated food (10.4\%) and exposure to infected contacts $(11.9 \%)$ were reported most frequently.

A total of $281 \mathrm{HAV}$ infections (10.7\%) acquired in Switzerland were reported in patients with foreign nationality, whereas 701 cases $(25.2 \%)$ were documented in the travel-associated group. Five hundred seventy-three $(82 \%)$ of these travelers were classified as having visited friends and relatives. They reported a travel history to their country of origin, mainly in southern Europe, West Asia (Turkey), or a developing country. The proportion of those visiting friends and relatives among all travelers developing hepatitis A increased from $15.5 \%$ in $1988-1993$ to $28.2 \%$ in 2000-2004. Infections in those visiting friends and relatives were predominantly observed in those $0-14$ years old, whereas overall, most patients were 15-29 years old.

HAV infection was diagnosed mainly during summer and autumn for both autochthonous and imported infections. A second peak in spring was detected for travelers after stays in Southeast Asia and at Caribbean destinations. Additionally, report of exposure to an infected contact as outcome variable was associated with absence of travel history (OR, 2.60; 95\% CI, 2.25-3.02) independently by logistic regression analyses.

For patients with HAV infection with travel history as dependent variable, logistic regression analyses identified younger age (OR, 1.04; 95\% CI, 1.01-1.07), foreign nationality (OR, 3.58 ; 95\% CI, 2.88-4.45), reported exposure to contaminated 
Table 1. Demographic characteristics and travel histories for hepatitis A virus (HAV)-infected subjects ( $n=6592)$.

\begin{tabular}{|c|c|c|c|c|c|}
\hline \multirow[b]{3}{*}{ Factor } & \multicolumn{4}{|c|}{ No. (\%) of subjects } & \multirow[b]{3}{*}{$P^{a}$} \\
\hline & \multirow{2}{*}{$\begin{array}{l}\text { All cases, } \\
\text { 1988-2004 }\end{array}$} & \multicolumn{3}{|c|}{ Travel-related cases } & \\
\hline & & 1988-1993 & 1994-1999 & $2000-2004$ & \\
\hline Imported from abroad & $2784(42.2)$ & 1420 (39.9) & $991(46.7)$ & $373(41.2)$ & \\
\hline Exposure in Switzerland & 2631 (39.9) & $\ldots$ & $\ldots$ & $\ldots$ & \\
\hline Unknown & $1177(17.9)$ & $\ldots$ & $\ldots$ & $\ldots$ & \\
\hline \multicolumn{6}{|l|}{ Reported exposure risk ${ }^{b}$} \\
\hline Injectable drug use & 1033 (39.3) & $70(4.9)$ & $10(1.0)$ & 0 & \\
\hline Sexual contact & $79(3.0)$ & $9(0.6)$ & $21(2.1)$ & $4(1.1)$ & \\
\hline Contact with patient infected with HAV & $880(33.4)$ & $147(10.4)$ & $157(15.8)$ & $27(7.2)$ & \\
\hline Contaminated food or water & $114(4.3)$ & $58(4.1)$ & $92(9.3)$ & $141(37.8)$ & \\
\hline Blood transfusion & $7(0.3)$ & $4(0.3)$ & $1(0.1)$ & 0 & \\
\hline Health profession & $36(1.4)$ & $19(1.3)$ & $14(1.4)$ & 0 & \\
\hline Other & $54(2.1)$ & 19 (1.3) & $31(3.1)$ & $14(3.8)$ & \\
\hline Unknown & $428(16.3)$ & $1094(77.0)$ & $665(67.1)$ & $187(50.1)$ & \\
\hline \multicolumn{6}{|l|}{ Sex } \\
\hline Female & 2424 (36.8) & $523(36.8)$ & 390 (39.4) & 147 (39.4) & NS \\
\hline Male & 4148 (62.9) & $893(62.9)$ & $597(60.2)$ & $224(60.1)$ & Referent \\
\hline Not available & $20(0.3)$ & $4(0.3)$ & $4(0.4)$ & $2(0.5)$ & \\
\hline \multicolumn{6}{|l|}{ Age group, years } \\
\hline $0-14$ & 1164 (17.7) & $195(13.7)$ & $283(28.6)$ & $129(34.6)$ & $<.001$ \\
\hline $15-29$ & $2647(40.2)$ & 581 (40.9) & $229(23.1)$ & $79(21.2)$ & $<.001$ \\
\hline $30-44$ & $1633(24.8)$ & $392(27.6)$ & $278(28.1)$ & $91(24.4)$ & Referent \\
\hline $45-59$ & $763(11.6)$ & $182(12.8)$ & $149(15.0)$ & 57 (15.3) & NS \\
\hline$>60$ & 352 (5.3) & $57(4.0)$ & $50(5.0)$ & $17(4.6)$ & NS \\
\hline Unknown & $33(0.5)$ & $13(0.9)$ & $2(0.2)$ & 0 & \\
\hline \multicolumn{6}{|l|}{ Nationality } \\
\hline Swiss & 4339 (65.8) & $889(62.6)$ & 531 (53.6) & $198(53.1)$ & Referent \\
\hline Foreign & 1179 (17.9) & $296(20.8)$ & $288(29.1)$ & 117 (31.4) & $<.001$ \\
\hline Unknown & 1074 (16.3) & 235 (16.5) & $172(17.4)$ & 58 (15.5) & \\
\hline \multicolumn{6}{|l|}{ History of travel } \\
\hline Africa & $568(20.4)$ & $315(22.2)$ & 167 (16.9) & $86(23.1)$ & \\
\hline Latin America/Caribbean & $402(14.4)$ & $213(15.0)$ & $129(13.0)$ & $60(16.1)$ & \\
\hline Asia & $560(20.1)$ & $284(20.0)$ & 197 (19.9) & $79(21.2)$ & \\
\hline Europe/North America & $1033(37.1)$ & $489(34.4)$ & $426(43.0)$ & $118(31.6)$ & \\
\hline Australia/Pacific & $15(0.5)$ & $4(0.3)$ & $9(0.9)$ & $2(0.5)$ & \\
\hline Unknown & $206(7.4)$ & $115(8.1)$ & $63(6.4)$ & $28(7.5)$ & \\
\hline \multicolumn{6}{|l|}{ Season of onset ${ }^{c}$} \\
\hline Winter (January-March) & $1533(23.3)$ & $349(24.6)$ & $190(19.2)$ & $54(14.5)$ & \\
\hline Spring (April-June) & 1075 (16.3) & $276(19.4)$ & $134(13.5)$ & $56(15.0)$ & \\
\hline Summer (July-September) & $1396(21.2)$ & $352(24.8)$ & $282(28.5)$ & $97(26.0)$ & \\
\hline Autumn (October-December) & $1677(25.4)$ & $369(26.0)$ & $201(20.3)$ & $99(26.5)$ & \\
\hline Unknown & 911 (13.8) & $74(5.2)$ & $184(18.6)$ & $67(18.0)$ & \\
\hline \multicolumn{6}{|l|}{ Course of disease } \\
\hline Hospitalization & $1424(21.6)$ & $237(16.7)$ & 197 (19.9) & $100(26.8)$ & \\
\hline No hospitalization & $2907(44.1)$ & 766 (53.9) & $529(53.4)$ & $1(0.3)$ & \\
\hline Unknown & 2261 (34.3) & $417(29.4)$ & $265(26.7)$ & 272 (72.9) & \\
\hline
\end{tabular}

NOTE. $P<.05$ was considered statistically significant. NS, not significant.

a Nonparametric test for trend developed by Cuzick [10], an extension of the Wilcoxon rank sum test.

b In decreasing order of exclusion; in the "all cases" column, data are for the cases acquired in Switzerland.

${ }^{c}$ Reported as date of diagnosis or date of manifestation.

food (OR, 2.42; 95\% CI, 1.73-3.38), reported exposure to an infected contact (OR, 0.46; 95\% CI, 0.37-0.56), and manifestation or diagnosis of HAV infection in summer (OR, 1.60; 95\% CI, 1.34-1.92) as independently associated factors.
Hospitalization was indicated in $19.2 \%$ of imported HAV infections, compared with $21.8 \%$ of cases of hepatitis A acquired in Switzerland $(P<.001)$. No fatalities due to hepatitis A were recorded that were clearly associated with travel and were not 
attributed to any concomitant condition. The proportion of patients aged $\geqslant 50$ years was $11.3 \%$ and $11.9 \%$ for HAV infections acquired in Switzerland and abroad, respectively.

Both the absolute number of travel-associated HAV cases and the attack rates among international travelers to destinations of high or intermediate risk of transmission declined over the study period (table 2). Travel within Europe or to North America is currently associated with a crude attack rate of $<1.0$ cases per 100,000 travelers. An intermediate attack rate of 1.04.0 cases per 100,000 travelers was found for travelers to various destinations in Asia, the Caribbean, or Central America. For African destinations (excluding South Africa), South America, and the Indian subcontinent, crude attack rates exceeded 4.0 cases per 100,000 travelers. The corresponding incidences per month among nonimmune subjects varied between 6.0 and 30.0 cases per 100,000 travelers, with highest rates found for Africa, south-central Asia (mainly the Indian subcontinent), and Latin America. Figure 1 shows selected country-specific data. As shown in table 3, the estimated immunization-attributed reduction in incidence showed a region-specific distribution and varied between $35.0 \%$ and $61.8 \%$.

\section{DISCUSSION}

The actual overall attack rates of HAV infections among travelers outside industrialized countries ranged between 1.0 and 7.0 cases per 100,000 travelers. The corresponding incidences for nonimmune travelers varied between 6.0 and 30.0 cases per 100,000 months of stay in virtually all developing countries. That is 10 to 50 times lower than the 300 cases per 100,000 reported 2 decades ago $[1,4]$. Obviously, this decrease mirrors mainly improved sanitary conditions, at least where travelers usually consume food and beverages. For the destination Mexico, an incidence of 6.2 cases per 100,000 person-months was registered in the period 2000-2004. Because hardly any travelers from Switzerland visit friends and relatives in this country, this documents the risk for tourists and business travelers. The monthly incidence was particularly high for travelers to Latin America and was significantly higher than for travelers to Southeast Asia $(P=.009)$. Similar incidences were found for British [11] and Canadian travelers (33 cases per 100,000 person-months of travel $[3,12]$.

Southern Europe no longer is a high-risk destination, compared with other parts of Europe, whereas travel to more remote parts of eastern Europe is clearly associated with the risk of acquiring HAV infection [13]. An Italian case-control study [14] found that the risk increased by a factor of 3 for travelers to southern or eastern Europe, compared with no travel. Popular tourist destinations in North Africa (e.g., Egypt, Morocco, and Tunisia) or West Asia (e.g., Turkey), often chosen for shortterm visits, clearly are regions with high risk. This stands in contrast to the official US source that lists Turkey as country with intermediate risk only [15]. Short-term visitors are of special concern, because they are often frequent travelers with a cumulative exposure to HAV [1]. Stays in luxury hotels by no means are exempt from risk [12]; this has recently been demonstrated by an outbreak $(n=352)$ among mainly German tourists who had stayed in a first-class hotel in Hurghada, Egypt [16]. Conflicts in a particular region result in destruction of infrastructure and a decline in sanitary conditions. The transient increase in the HAV attack rates among Swiss travelers to former Yugoslavia between 1994 and 1999 illustrates this.

The proportion of travel-associated cases among all reported HAV infections varies greatly between countries. This may depend in part on the data source. For Switzerland, the average proportion of all imported infections (42\%) and of infections associated with stays exclusively in high- or intermediate-risk countries for HAV (27\%) are similar to or higher than data

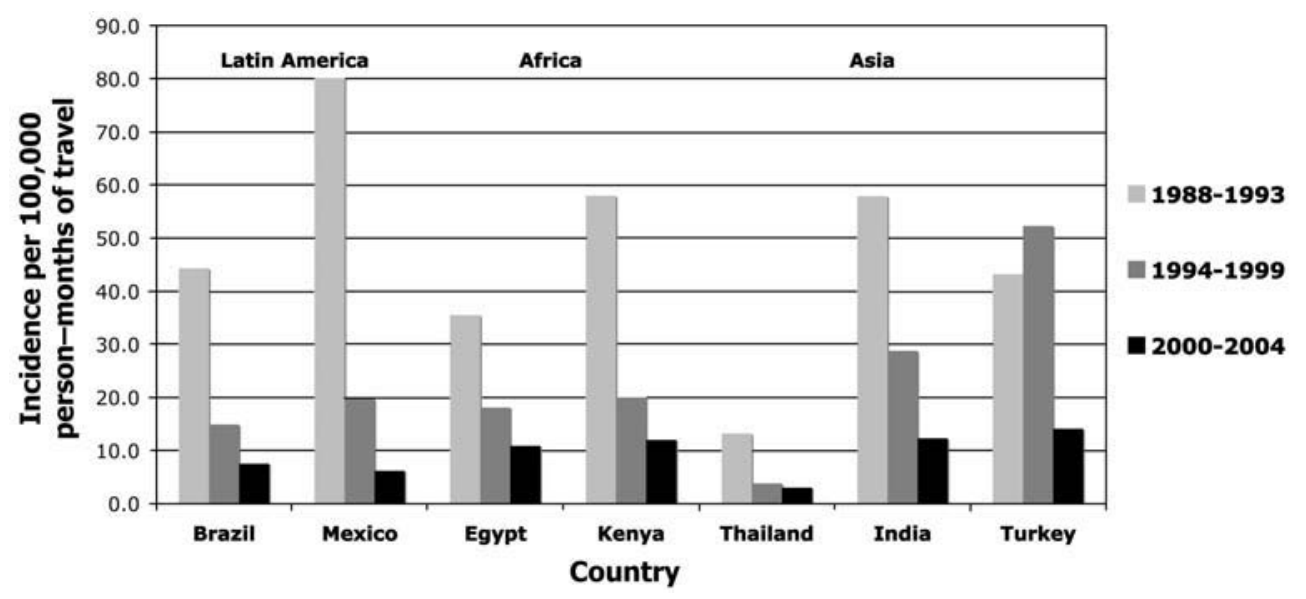

Figure 1. Incidences of hepatitis A virus infections in selected frequently visited countries, 1988-2004. Incidences for the years $2000-2004$ (per 100,000 person-months of travel): Brazil, 7.5; Egypt, 10.9; India, 12.3; Kenya, 12.0; Mexico, 6.2; Thailand, 3.0; and Turkey, 14.1. 


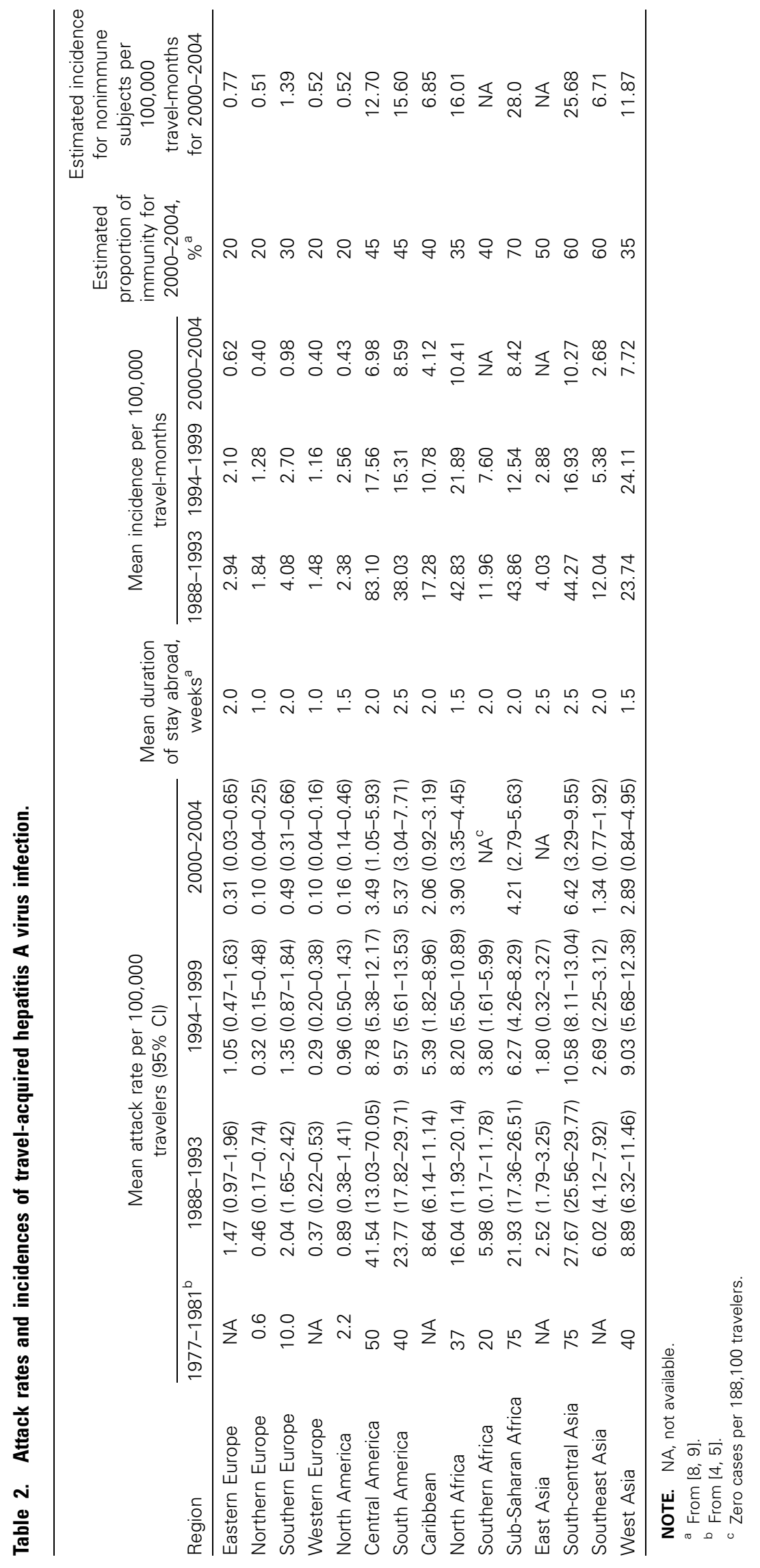


Table 3. Estimated reduction in incidence among travelers through immunity against hepatitis A virus (HAV).

\begin{tabular}{|c|c|c|c|}
\hline Selected region & $\begin{array}{l}\text { Reduction in } \\
\text { incidence, \% }\end{array}$ & $\begin{array}{l}\text { Monthly incidence } \\
\text { per } 100,000 \\
\text { extrapolated from } \\
\text { prevaccination era } \\
\text { to } 2000-2004^{a}\end{array}$ & $\begin{array}{c}\text { Total } \\
\text { monthly incidence } \\
\text { per } 100,000 \\
2000-2004^{b}\end{array}$ \\
\hline Regions with high to intermediate risk for HAV & 35.0 & 10.0 & 6.5 \\
\hline South America & 52.2 & 18.0 & 8.6 \\
\hline North Africa & 48.0 & 20.0 & 10.4 \\
\hline Sub-Saharan Africa & 61.8 & 22.0 & 8.4 \\
\hline South-central Asia & 58.8 & 25.0 & 10.3 \\
\hline
\end{tabular}

a The trend before 2000-2004 was evaluated by using the incidences of HAV infection before widespread vaccine use (1971-1993).

This represents a surrogate of effects other than vaccination (e.g., improvements of sanitary conditions at destination).

${ }^{\mathrm{b}}$ Data are from table 2.

from European and North American studies published after 1990: 25\% (United Kingdom) [17], 28\% (Italy) [14], up to one-third (Canada) $[12,18]$, and $32.6 \%$ to $>50 \%$ (Germany) $[19,20]$. The very low proportion of $4 \%-6 \%$ registered in the United States thus far [21] may illustrate that exposure risk data were assessed differently with respect to the order of exclusion of the travel history.

Travel-associated HAV infections differed with nationality and age of the patients. Foreign nationals (25.2\%) were slightly overrepresented compared with the foreigners among Swiss residents (20\%). The majority of foreigners were classified as migrants or persons visiting friends and relatives, and this proportion increased during the study period. Adults likely to be immune because of previous exposure to HAV ask less frequently for pretravel health advice before traveling with their nonimmune Swiss-born children to their high-risk countries of origin. Often they visit areas outside usual tourist routes and have a longer duration of stay, including closer contacts to the local population [22-24]. As shown by the multivariate analysis, the patients who had traveled to visit friends or relatives were younger than those with HAV acquired in Switzerland; their infections occurred more often in the summer months, the usual vacation time of those visiting friends and relatives; and exposure to contaminated food was less frequently reported (data not shown), which may indicate a decreased awareness of exposure risks. Therefore, special attention is needed to reach those traveling to visit friends and relatives for pretravel health advice. In contrast, senior travelers ( $\geqslant 50$ years; $11.9 \%$ ) were rather underrepresented, because $19 \%$ of Swiss travelers belong to this age group; this anomaly may be explained by higher levels of previously naturally acquired immunity or by safer patterns of behavior $[4,25]$.

The spread of imported HAV infections from children to household contacts, to other children, and to professionals in schools or day care centers has been previously described [2629]. Transmission of imported hepatitis A by food handlers has been described in Switzerland [30] and elsewhere [31].
The validity of the data is linked to the reliability of the databases used. Because both laboratory and physicians are required to report diagnosed cases of HAV infection independently, the sensitivity of the surveillance system is considered to be high $(\sim 80 \%)$. The proportion of cases with missing physician-based information has decreased from $29.3 \%$ in 1988 to $8.6 \%$ in the past 2 years. Additional sources of underreporting may be asymptomatic infection or cases diagnosed and treated abroad. Thus, the attack rates and incidences are rather underestimated. Given the fact that annual travelers' statistics are usually based on national information, they represent rough estimates that gain more robustness through the classification into regions. Pretravel medical advice was used as a surrogate to estimate immunity against $\mathrm{HAV}$, because we were missing recent serological data about immunization coverage among travelers. With regard to validity, the resulting incidences for nonimmune subjects and those for nonimmune subjects, extrapolated from the prevaccination era, show consistency.

When hepatitis A vaccination [32, 33] was introduced in Switzerland early in 1992, it was recommended for risk groups only. This strategy was only partially effective, because many travelers, mainly those visiting friends or relatives or those to popular tourist destination close by (across the Mediterranean for Europeans, Mexico for US and Canadian travelers), often fail to seek travel health advice. Despite considerable reductions in incidence attributed to the impact of HAV vaccination and despite decreasing population-based HAV seroprevalence at many destinations $[34,35]$, there is still potential for improvement. We should focus on the risk perceptions of travelers, such as those visiting friends and relatives and those going to popular destinations. Thus, through addressing hepatitis A risk among those visiting friends and relatives, we would not only protect individuals but may also potentially disrupt the transmission cycle in communities abroad and back home [22, 36]. Targeted routine HAV vaccination of at-risk groups could be effective, as was shown with HAV vaccination of children of Turkish and Moroccan origin in Amsterdam [37]. Further stud- 
ies are needed to assess the traveler-based lifetime risk of exposure to HAV and to evaluate in more depth the impact of different vaccination strategies considering travelers from countries with very low HAV endemicity $[36,38,39]$.

The number of HAV infections decreased substantially over the past 2 decades for imported cases as well as for infections acquired in Switzerland. This is only partly the result of HAV vaccination. Nonimmune travelers still have an incidence of 6.0-30.0 per 100,000 person-months at risk destinations. The risk at nearby destinations, such as Mexico for Americans or Turkey and North Africa for Europeans, is often underestimated. Two strategic options for prevention of HAV infection need to be considered: (1) targeting tourists unaware of risk of HAV infections at close destinations and those visiting friends and relatives, and (2) universal hepatitis A immunization. In populations with a high proportion of lifetime HAV exposure, the latter may be appropriate.

\section{Acknowledgments}

Potential conflicts of interest. R.S. has accepted a fee for speaking, organizing, and chairing education, consulting, and/or serving on advisory boards for and also reimbursement for attending meetings and funds for research from Berna Biotech, Chiron Behring, GlaxoSmithKline, Novartis, Roche, Salix Pharmaceuticals, and Sanofi Pasteur. All other authors: no conflicts.

\section{References}

1. Steffen R, Kane MA, Shapiro CN, et al. Epidemiology and prevention of hepatitis A in travelers. JAMA 1994;272:885-9.

2. Mutsch M, Tavernini M, Marx A, et al. Influenza virus infection in travelers to tropical and subtropical countries. Clin Infect Dis 2005; 40:1282-7.

3. Teitelbaum P. An estimate of the incidence of hepatitis A in unimmunized Canadian travelers to developing countries. J Travel Med 2004; 11:102-6.

4. Steffen R. Risk of hepatitis A in travellers. Vaccine 1992; 10(Suppl 1):S69-72.

5. Steffen R, Regli P, Grob PJ. Wie gross ist das Risiko einer Reisehepatitis? Schweiz Med Wochenschr 1977; 107:1300-7.

6. Travelers statistics 1988 to 2002. Berne, Switzerland: Swiss Federal Office of Statistics, 2003.

7. United Nations Population Division. World population prospects: the 2002 revision database. Available at: http://esa.un.org/unpp/definition.html. Accessed 8 February 2005.

8. Van Herck K, Castelli F, Zuckerman J, et al. Knowledge, attitudes, and practices regarding travel-related infectious diseases: methodology and results from an airport survey in Europe. J Travel Med 2004; 11:1-7.

9. Gisler S, Steffen R, Mutsch M. Knowledge, attitudes, and practices among travellers to tropical and subtropical countries. Praxis 2005; 94:967-74.

10. Cuzick J. A Wilcoxon-type test for trend. Stat Med 1985;4:87-90.

11. Behrens R, Carroll B. A decade of travel-associated hepatitis A, typhoid and malaria, vaccine and travel trends in England and Wales. In: Program and abstracts of the 8th International Conference of Travel Medicine (New York). Stone Mountain, GA: International Society of Travel Medicine, 2003:121.

12. De Serres G, Duval B, Shadmani R, et al. Ineffectiveness of the current strategy to prevent hepatitis A in travelers. J Travel Med 2002; 9:10-6.

13. Nothdurft HD, Dahlgren A, Gallagher EA, et al. Consensus recommendations on hepatitis A and hepatitis B vaccination for travel destinations in Central and Eastern Europe and the Mediterranean region. In: Program and abstracts of the 9th International Conference of Travel Medicine (Lisbon). Stone Mountain, GA: International Society of Travel Medicine, 2005:105.

14. Ciccozzi M, Tosti ME, Gallo G, et al. Risk of hepatitis A infection following travel. J Viral Hepat 2002; 9:460-5.

15. Health information for international travel 2005-2006. Atlanta: Centers for Disease Control and Prevention, 2005.

16. Frank C, Walter J, Muehlen M, et al. Large outbreak of hepatitis A in tourists staying at a hotel in Hurghada, Egypt, 2004-orange juice implicated. Eurosurveill Wkly 2005; 10:2-4.

17. Crowcroft NS. Guidelines for the control of hepatitis A virus infection. Commun Dis Public Health 2001;4:213-27.

18. Duval B, Boucher F, Dion R, et al. Contrôle de l'hepatite A par l'immunisation au Quebec: rapport final du groupe de travail. Quebec: Ministère de la santé et des service sociaux du Quebec, 1997.

19. Diel R, Schneider S. Transmission of hepatitis A in Hamburg, Germany, 1998-1999-A prospective population based study. Eur J Epidemiol 2001; 17:175-82.

20. Thierfelder W, Meisel H, Schreier E, Dortschy R. Prevalence of antibodies against hepatitis $\mathrm{A}, \mathrm{B}$ and $\mathrm{C}$ viruses among the German population. Gesundheitswesen 1999; 61(suppl 2):S110-4.

21. Bell BP, Shapiro CN, Alter MJ, et al. The diverse patterns of hepatitis A epidemiology in the United States-implications for vaccination strategies. J Infect Dis 1998; 178:1579-84.

22. Bacaner N, Stauffer B, Boulware DR, Walker PF, Keystone JS. Travel medicine considerations for North American immigrants visiting friends and relatives. JAMA 2004; 291:2856-64.

23. Angell SY, Cetron MS. Health disparities among travelers visiting friends and relatives abroad. Ann Intern Med 2005; 142:67-72.

24. Fulford M, Keystone JS. Health risks associated with visiting friends and relatives in developing countries. Curr Infect Dis Rep 2005; 7: $48-53$.

25. Studer S, Joller-Jemelka HI, Steffen R. Prevalence of hepatitis A antibodies in Swiss travellers. Eur J Epidemiol 1993; 9:50-4.

26. Van der Eerden LJ, Bosman A, Van Duynhoven YT. Surveillance of hepatitis A in the Netherlands 1993-2002. Ned Tijdschr Geneeskd 2004; 148:1390-4.

27. Conzelmann-Auer C, Ackermann-Liebrich U, Herzog C, Bachlin A. Hepatitis A outbreak in a kindergarten. Schweiz Med Wochenschr 1992; 122:1559-66.

28. Franco E, Giambi C, Ialacci R, Coppola RC, Zanetti AR. Risk groups for hepatitis A virus infection. Vaccine 2003;21:2224-33.

29. Nainan OV, Armstrong GL, Han XH, et al. Hepatitis A molecular epidemiology in the United States, 1996-1997: sources of infection and implications of vaccination policy. J Infect Dis 2005; 191:957-63.

30. Swiss Federal Office of Public Health. Outbreak of hepatitis at the Canton of Solothurn [in German]. Bulletin Bundesamt für Gesundheit 2002; 7:112-5.

31. Fiore AE. Hepatitis A transmitted by food. Clin Infect Dis 2004; 38 : 705-15.

32. Craig AS, Schaffner W. Prevention of hepatitis A with the hepatitis A vaccine. N Engl J Med 2004; 350:476-81.

33. Van Herck K, Van Damme P. Inactivated hepatitis A vaccine-induced antibodies: follow-up and estimates of long-term persistence. J Med Virol 2001; 63:1-7.

34. Jacobson KH, Koopman JS. Declining hepatitis A seroprevalence: a global review and analysis. Epidemiol Infect 2004; 132:1005-22.

35. Poovorawan Y, Chatchatee P, Chongsrisawat V. Epidemiology and prophylaxis of hepatitis: a global perspective. J Gastroenterol Hepatol 2002; 17(Suppl):S155-66.

36. Scheifele DW. Hepatitis A vaccines: the growing case for universal 
immunisation of children. Expert Opin Pharmacother 2005; 6: 157-64.

37. Richardus JH, Vos D, Veldhuijzen IK, Groen J. Seroprevalence of hepatitis A virus antibodies in Turkish and Moroccan children in Rotterdam. J Med Virol 2004; 72:197-202.

38. Samandari T, Bell BP, Armstrong GL. Quantifying the impact of hepatitis A immunization in the United States, 1995-2001. Vaccine 2004; 22:4342-50.

39. Postma MJ, Bos JM, Beutels P, Schilthuis H, van den Hoek JAR. Pharmaco-economic evaluation of targeted hepatitis A vaccination for children of ethnic minorities in Amsterdam (The Netherlands). Vaccine 2004; 22:1862-7. 